\title{
Investigating Factors Affecting Science Teachers' Performance and Satisfaction toward their Teaching Process at Najran University for Girls' Science Colleges
}

\author{
Amel Thafer Alshehry ${ }^{1}$ \\ ${ }^{1}$ School of Education, Najran University, Najran, Saudi Arabia \\ Correspondence: Amel Thafer Alshehry, Department of Curriculum and Teaching Methods, School of Education, \\ Najran University, Najran, Saudi Arabia. E-mail: atalshehry@nu.edu.sa \\ Received: April 2, 2014 \\ Accepted: April 21, 2014 \\ Online Published: April 22, 2014 \\ doi:10.5430/ijhe.v3n2p73 \\ URL: http://dx.doi.org/10.5430/ijhe.v3n2p73
}

\begin{abstract}
In Saudi educational system, many factors have led to a various need for teaching qualifications in higher educational institutions. One main aim of this study was to determine the perception of college teachers on how to assess the effectiveness of the teaching process and what most students consider when evaluating their teachers. Further, it aimed to investigate the problems that academic teachers face in providing well-planned and effective services. To determine teachers' perspectives, semi-structured interviews were conducted with 27 teachers selected at random from science departments at Najran University. It focused on several areas of teaching methods, such as curriculum programming, syllabus coverage of classes, teachers, and methods of effective teaching. Evaluation and student feedback was recorded. The collected data were analyzed through a list of key issues, concerns and themes to be discussed by the set of participants. The results revealed that teachers had some difficulties in addressing practical problems with implementing the current curriculum, using sufficient supplementation for teaching methods, and understanding validation of the evaluation process presented by students on the teachers' achievements. Based on these findings, it is crucial to take teachers' points of view into consideration in the development of the curriculum process, the exam system, resources, facilities and the evaluation system. Teacher involvement will create ownership and allow them to have an active role in teaching students with more devotion and commitment to evaluation. This will lead to significant improvement in teaching methods of science at all college levels.
\end{abstract}

Keywords: Teaching of science, Evaluation, Decision making, Professional development, Curriculum planning, Education system

\section{Introduction}

Perceptions towards the beginning and development of education in Saudi Arabia have been investigated by a number of previous studies over the last 20 years, from the first case study collected and published by Abdel-Al (1988), Al-Dawood (1996) and Abdel (1970) to the most recent study conducted by Alkahzim (2006). All of these previous studies reported a serious lack of information and data regarding the teaching of science, roles and activities in girls' colleges. However, such investigations are important for the future development and improvement of science colleges in Saudi Arabia. One main problem in investigating the process of teaching science is the lack of a clear explanation of the role and task of science teachers. Typically, the role is unclear not only to students, lecturers and assistant teachers, also to the principals of the colleges (Alshehry, 2009). In practice, there are inconsistencies between the real teaching achievement and the role provided to teachers, which depends on the activities, methods, and learning activities provided to students.

When the educational system and science college itself fail to clearly define and provide the opportunity to develop and improve teaching skills and knowledge, teachers often focus on their role mainly from their own perspectives (Zaiton, 2004). This can usually can be found defaults to having their own decision and advancement in higher education science college. In the UK, independent training could be fostered by holding workshops to improve their professional teaching skills which an ward to good teaching achievement year by year by for example providing them with a participation in regional and international conferences, meetings, seminars, or departmental committees (Brabazoan and Altbach, 2009: 38). However, in Saudi Arabia, most of studies in higher education have focused mainly on boys' colleges. To date, no studies have concentrated on the role of effective teaching process and 
performance within girls' colleges, and particularly in specialized levels of undergraduate students (Baki, 2004). Therefore, this study was conducted in a college where female students are enrolled in their separated colleges, that gender in not under investigation.

The effective teaching process is also known as an academic process in which students are motivated to learn in a way that has a positive influence on how students think, act and feel (Smittle, 2003). This process reflects the combined relation between teachers and students in which teachers can indicate their positive and successful teaching process from the impression of students and how they could get the best way of teaching by interacting the way they learn from their teaching. According to Alkhazim (2006), teaching has always been a challenging profession in which teachers are being asked to teach by problem solving and improving teaching skills to gain effective teaching and learning practices. However, a teacher also plays an important role in effective teaching processes because teacher practices correlate to student performance. Effective teachers will organize the classroom in a good way and understand the individual abilities of their process. Teaching can be performed in an effective and positive way to help students achieve their goals and allow students to obtain a clear idea of what they will be learning, including their assignments and policy of grading. Moreover, lecturing with a clear way of teaching gives them a chance to learn more on their own. Therefore, higher educational institutions (universities) need to provide such facilities to students that satisfy students' needs (Douglas et al., 2006). Thus, practice and facilities are perceived to be the most effective method of effectual learning and the main factor that could be directly related to students' satisfaction (Pathak and Rahman, 2013).

\section{Literature Review of the Effective Process of Teaching Science}

Discussing the method of teaching science in Saudi Arabia is largely based on the recent approach of teaching and learning of science education, encouraging more effective teaching that depends on student interactions and attitudes. This approach focuses on students' critical thinking and independent learning as a new trend and way of teaching and learning in an advanced country (DeHann, 2005, DebBurman, 2004 and Udovic et al., 2002).

To achieve good teaching, the best approach for teaching methods in education are required. Teachers need to select from different techniques of teaching methods and strategies in the colleges and classroom (Melita \& Peklej, 2007). Lesson planning is important before leading lectures in class. The selection of teaching methods is important on the basis of students' knowledge with some learning process in the presented academic syllabus or curriculum (Carpenter, 2006). In addition, teaching methods and facilities need to be adopted by teachers to increase the learning abilities and achievement in effective ways, such as presenting interactive lectures, facilitating group discussions during class to allow students to express opinions, and student presentation of seminars and workshop to expand their capacities (Henson and Eller, 2012). An effective teaching method needs to include students in learning activities and promote their interest, mostly in science, and develop scientific process skills and development. Therefore, students need to develop skills with traditional lectures and laboratory work. Innovative methods need to be presented to students from time to time to give them a chance to integrate their knowledge to their existing ideas. Also, it is critical to develop and renew the teaching and method of science to get student satisfaction about their learning process (Alshehry, 2009). Effective teaching evaluation is also important in the use of different teaching processes, and teachers need to develop new teaching with innovative teaching strategies for use in both traditional and new instructional methods. Evaluation is therefore a process by which the levels of achieving goals and aims are easy to understand by the teachers and students (Goe et al., 2008). Therefore, it is important to know how much the teaching process has become effective, which can be perceived by the perception of students and teachers towards different teaching methods. Thus, the learning process can be improved by effective teaching methods and evaluation of teaching by students. Second, this increases the opportunities for teachers to develop their professional involvement in teaching and be recognized for their teaching. Third, it helps students recognize the importance of student involvement in shaping educational goals and practice (Alshehry, 2009). Fourth, of student evaluation explores the teaching effectiveness and the roles affected the teaching process (Addison and Best, 2009).

This, however, shows a strong relationship between the effects of teaching methods and obtaining positive feedback from student evaluations. It is assumed that students who receive a fair grades will evaluate their instructors more positively (Cherry et al., 2003). In comparison, students who are highly reached to success grades in a course may work harder to get a higher grades. Their success however, may lead them to evaluate their faculty member effectively and relate their high grades to the effective instructions (Addison and Best, 2006). Moreover, some studies show that student interest and positive evaluation feedback is related to the value of the course and stimulation that are affected by the course teaching evaluation (Remedios and Lieberman, 2008). Taking all these 
previous studies into consideration, it is evident that students evaluate lecture and teaching based on specific reasoning, mostly for personal and academic reasons.

In this matter, the successful and effective implementation of each college course with the syllabus depends upon a number of conditions, such as well-designed curriculum and a timetable presented in the syllabus. However, the accessibility of teachers outside of class, regularity of class depending on, transparency in evaluation and student grade is for students (Jadoon, Jabeen and Zeba, 2012). Because most of the learning process occurs during the classroom setting, student involvement and engagement in class are very important for successful teacher evaluation and support of the teachers' professional development for the classroom management. These issues were measured in this study because of the increased attention that attracted an international higher educational studies.

\subsection{Studies of Science Education in Saudi Arabia Higher Education}

One of the earliest studies that examined the perceptions of science teachers in Saudi higher education was conducted by Salamah (2003). This study was investigated the actual situation and teaching process perceived directly by the teachers. A study collected by Alshehry (2009) explored the perceptions of the academic staff such as principals, lecturers and assistant teachers in a girls' college in Saudi Arabia concerning curriculum planning and development, teaching methods of science, how these influenced their beliefs and the professional development of teaching science. The study took place in three science colleges in Riyadh (the capital) with all female respondents, using qualitative methods (semi-structured interviews) and observation. Individual interviews were conducted within the three principals of each college, fifteen lecturers and fifteen assistant teachers.

The findings of the study showed many factors affecting the participants in their performance of teaching science. Moreover, principals saw their leadership enabling them to practice their role with a lack of decision making. Most teachers wanted to be involved in the decision making process in science education according to the needs of students' learning. Many methods used in teaching science were traditional and teacher-centered with self-directed learning not fully used. These results were supported by the findings of professional development with more need for professional improvement of skills and knowledge. Ashehry concluded that although great support and attention was placed on the higher educational development, the perception of teaching process provided remained unsatisfactory to meet the needs of student learning. Furthermore, the teaching of science remained unclear and a great effort appeared to be concentrated on traditional and teacher-centered approaches which would affect students encouragement and interaction during the lecture.

The most recent study carried out by Salamah (2002) highlighted the need for science teachers to develop academic guidance and professional knowledge for good teaching performance. Furthermore, the study by Zaiton (2004) focused on the need to provide good equipment, supplements and facilities to enhance the teaching of science for teachers to fully clarify and illustrate scientific context. However, the study of Sarayrah (2003) also supported this in Jordan as an Arab country with the same system of higher education as in the Middle East. The results show the lack of student credibility to evaluate the way the teachers taught, which could provide insight into their positive and negative points in teaching science with greater improvement in science education in the future. These higher educational system as supported by Salamah (2002) was illustrated by Alkhazim (2006), which criticized the model used in teaching with a traditional type and simple methods, including attending classes and presenting simple lectures with no illustrational aids. These teaching structures place students as only an audience listening to the lecturers, only to take notes during and at the end of classes.

\subsection{Gaps in the Literature and Research Questions}

The literature regarding the science education and teaching of science in Saudi Arabia higher education is lacking. Relevant studies are discussed in this report. However, some studies reviewed educational systems in general and some studies investigated the teaching of science in some Arab countries, which is quite similar to the educational review in Saudi Arabia. Furthermore, there are few reports on the educational needs, factors that affect teaching of science, science teacher needs and professional development. Moreover, many previous studies focused on the general educational system (intermediate and high school) with few studies in the higher educational level (college and university).

Therefore, this study was conducted to fill the gaps and ambiguity in the literature by focusing on the perception of academic teachers' regarding their teaching performances and effectiveness in the areas of improving their teaching methods and skills, planning their curriculum, coverage of the syllabus and how real student evaluation feedback could affect the development of teaching professionals. It is hoped that the research will make a contribution to exploring the teaching process faced by science teachers at the higher educational girls colleges in Saudi Arabia. The 
findings could help principals as a leaders to better understand the current situation and the roles of teacher and teaching processes to provide their teaching more effectively. Moreover, it could help other colleges in developing their programs for college teachers. Having a better understanding of factors that affect the teachers' process of teaching would support universities and colleges to work collaboratively to fill the gaps between theory and practice regarding how science is taught, planned and practiced.

In this paper, special emphasis is given to investigating the teachers' perception towards factors affecting the teachers and their teaching process, curriculum and syllabus coverage, and the availability of process of evaluation feedback provided for students. To achieve this objective, the main aims were to:

explore the effective teaching methods provided for students with clear idea of what they will be learning, including their assignment, the facilities used, and how teaching gives them a chance to learn more on their own.

determine the relationship between the effecting of teaching methods and getting positive feedback from student evaluations.

(iii) identify teachers points of view in the development of curriculum process and the chance could be giving to cover and improve the teaching syllabus.

(iv) suggest recommendations for the future improvement in Saudi Arabia teaching and learning in science girls college.

To fulfill these aims, information was gathered specifying the following questions:

1) How do teachers think they could present the best way of teaching for an effective teaching process?

2) Are there any differences between student views in terms of student grades and academic success on the evaluation of lectures and teaching process?

3) What do teachers think about the curriculum presented and coverage of syllabus?

\section{Methods and Procedures}

For this study, a qualitative approach was employed and conducted to allow the research to benefit from the strength of the rich and deep information, and in some ways overcome their separate limitations. Semi-structured interviews with observation were conducted as a methods of qualitative data. It is important here that the qualitative approaches are better collected to answer the research questions with better deep answering of questions (Dodds at al., 1995). Using qualitative approaches, a small number of interviews increased the rich and depth information of the study, providing a deep complete data regarding the issue. In defining the research population for the present study, the Najran province was selected for sampling.

Although a few studies have conducted the perceptions of science teachers in the higher educational systems in each institution, most have been focused in the boys' sections within specific cities, such as Riyadh, Jeddah and Dammam. The educational system in Saudi Arabia is mainly controlled by the ministry of higher education, improvement, and development as the same roles applied as in other regions in the country as well. Teaching systems and models in the male sections are largely the same as in the women sections in higher educational colleges. As the purpose of collecting the data in this study was to investigate how teaching science was perceived by teachers, it was hoped that the findings could highlight the problems affected the teachers during teaching of their courses and take these problem into considerations. The focus of this study has not been previously explored before in detail by researchers in Saudi Arabia, which posed a challenge, particularly in effectively gathering data. After conducting a previous studies of the literature on teaching of the science curriculum, we decided to use a modified methods of observation used by Alshehry (2009) to investigate the ways of teaching of science as seen and presented for the students.

\subsection{Samples and Location of Research}

The sample of the study included 27 academic teachers in Najran University. The study was confined to these 27 teachers who taught science curriculum using various teaching methods and at different levels and in different majors of science in the Colleges of Art and Science and College of Education for girls. Most teachers were selected randomly from each of the college based on interview data collection by the researcher applying of the samples throughout the colleges. The final sample for the study consisted of 27 academic staff teachers who were coded with numbers from one to twenty seven.

The interview sample was drawn from participants who agreed to be interviewed. However, we decided to select teachers who had great experience, challenge and more knowledgeable in an investigation issues and more able to 
offer a useful information concerning their teaching process. The purposive sampling in qualitative research has been emphasized by several authors as Bogdan and Biklen (1992) noted that "the subject selection process for qualitative interviewing is not random sampling, but is purposeful in choosing subjects who may expand theory" (p. 87). Therefore, a purposive sampling technique was selected with the sample of 27 academic teachers with considerable experience with the students and programs in the college, and who were interesting to participate in the study.

\subsection{Lecturer Perceptions}

Most teachers supported their students' learning and activities, and most tasks were attached with the teaching methods relating to the academic, active and belief in their teaching methods, which were shown in their professional and educational development. However, most important teaching methods mentioned by teachers were helping their students to understand lectures in easy and successful ways with a higher stander of academic achievement. This also could be seen by student evaluation feedback about their learning outcome connecting with their developmental needs, providing them with information about the teaching process after each courses taken by them at the end of their semester. In contrast, teachers attached lower importance of connecting student needs to planning of their curriculum and coverage of syllabus, due to the students lower importance in interacting with them in class. On the other hand, teachers believe that students had a greater amount of activities encouraging their learning in educational issues and college interactive activities, such as workshops, discussions, self-learning and duties. Nevertheless, teachers also showed less involvement in making decisions regarding their teaching process needed, which could help their students develop their academic and social skills.

\subsection{Data Gathering Tools and Treatment of Data}

The required data were collected through administering interview questions prepared by the investigator based on established procedures in the literature. The same interview was used for both target groups. The main interview section was divided into three subsection according to objectives under consideration. A semi-structured method is a data collecting method in which a researcher draws a list of key issues, concerns and themes to be discussed by a selected set of participant with different interview sections. Section A contained two questions: first, related to international methods used, and second, focused on an effective teaching process satisfaction and support in the educational system. Section B concentrated on respondents views regarding quality and validity of the effective students evaluation, course grades at the end of each semester and how the evaluations were useful to them. As the study follows descriptive methods and the data collected were mainly of the interview type, descriptive methods were employed. Section $\mathrm{C}$ focused on the curriculum planning and syllabus organization, and inquires towards student views of curriculum distribution and activities.

\section{Interview Findings}

The interview findings are provided in three main sections. First, it explores the teachers' perceptions of the science courses taught. In the second section, their perceptions of the student views and evaluation process of their lectures and teaching process are discussed. The third section examines the presented science curriculum and planning with the satisfaction of syllabus coverage. Finally, a number of suggestions for the development of teaching and planning, department guidance, and learning outcomes in Saudi Arabia are considered.

\subsection{Teaching Methods Presented}

Questions 1: "What methods are used in the college and supplement provided?"

The results revealed that overall perception of most teachers is strong dissatisfaction (sixteen of the twenty seven interviewed), with $7 / 27$ satisfied to some extent. Four of the interviewed teachers (4/27) showed satisfaction and reported effective methods and facilities are available and used in teaching. For example, teacher 27 notes "yes they use corporative work, discussion group, teachers also use scaffolding to teach writing to some extent they use modern methods, technology and data show". Notably, very few teachers recorded strongly satisfaction so far in regards to knowledge of the teachers. To illustrate the major disagreement as dissatisfaction with the aids provide and the methods the teachers used for effective teaching with materials, use of facilities and supported aids in teaching were not at all satisfied as revealed by most of respondents such as teachers with stated code $(7,20 \& 21$ out of 27). To some extent, this is shown by respondents 19 and 25 who disagree in stating "strongly disagreed", while teachers 1 and 9 agreed with this view, and who also noted that "not supportive, need to be developed more in instructional resources". These teachers made the following assertion: "there is a lack of equipment and teaching aids which effect teachers enthusiasm, students learning and their interaction during the class". Because of this, they pay attention to the current situation of teaching science to the class and their failure of achieving a professional teaching performance. In other words, as stated in this previous result, the reason for the unqualified teaching 
methods is the lack of resources and facilities with the need to develop their professional knowledge as to how to teach science to undergraduates, providing them with full materials and training for learning.

Therefore, as some previous studies such as Alshehry (2009) suggested, the availability of resources is very important for the effective materialization of teaching and support for students' effective evaluation to their teaching. This could be achieved by focusing on resources like classrooms, library, reading room facilities, books and journals, Instructional Communications and Technology (ICT), audio visual aids, computers and Internet facilities. With regards to the teachers perceptions about the availability of information and resources, the majority of teachers believe that these facilities are important for student understanding and helping achieving a good percentage of degrees (Melita \& Peklej, 2007). To some extent, it is good to have some students activities during the classroom such as brainstorm groups discussions consisted with studies of Henson \& Eller (2012).

Question 2: "Do students realize the importance of evaluation and learning outcome?"

Most of the participants' responses expressed a number of views concerning student feedback about their evaluation of their teachers, their teaching methods and the curriculum presented. Two participants agreed that evaluations show the importance of helping students, especially the low students achievers with grades and of the teachers themselves by which could surely improve their performance and teaching methods. As one of these teachers pointed that "students' evaluation feedback should be considered and inserted in our requirement courses program including all the way we teach our students"'. Moreover, regarding their ethic professional, seven teachers had noted: "it is not true to some extent, teachers has no authority, they need to evaluate students in doing some activities, interaction during the class and critical thinking to get enough feedback about students levels". In addition, teacher 20 stated the use of evaluation feedback is of benefit "to some extent, it depend on the teachers training, experience and professional development with the need of more effective instructional teaching and up to date teaching strategies".

However, one teacher commented that "unfortunately, in our college the evaluation process is not helping at all, students need assessment to check their skills to give better understanding with the results", while teacher 26 said that the evaluation process "doesn't provide the real assessment of students learning and their skills all the time". The majority of participants (22 out of 27) stated that evaluation has not helped provide additional necessary information but instead "evaluate students on other activities in the class rather than the courses presented only they need to evaluate how the teacher provide them with research, quizzes, presentations". One teacher commented that "the evaluation we used is not enough to get a real view of students' goals, academic standard and teachers performance as well". However, taken together, these responses show that most of the teaching evaluations provided by teachers to their students involves comprehensive evaluation and examination achievement in all dimensions of student behavior. However, the majority of teachers mentioned above indicated that the evaluation system must be studied ahead of time to be more understandable by both the teachers and students. In line with this, one teacher added that "the perception of teacher respondents regarding the truth and reality of student feedback with the same teaching system presented to them needs to be truly reflected by the students' impression". In the same point, one teacher argued that "if the students' do not qualified well for the evaluation process and how is it important to them, I think the teacher must be concerned and blame themselves". In this case, students need to have a greater understanding and knowledge about the evaluation process and the validity of teachers' evaluations should be simpler for the students to understand (Goe et al., 2008). Therefore, students could be informed and be guided with these processes with some training and workshops, especially in the beginning levels before the evaluation to address specific points in the evaluation form. If these evaluation processes were truly and clearly achieved by student feedback of their evaluation, the process of improving teaching methods and the curriculum presented will be enhanced and performance will improve (Addison and Best, 2006).

In addition to focusing on the negative points presented by student evaluations, the feedback could help them improve and develop weak areas of teaching (Alshehry, 2009), which emphasizes their professional development. However, to be consistent with student responses, some students did evaluate their course and teachers' teaching systems and methods depending on the grades they received in the final and midterm exams, which in turn affected their teaching evaluation (Remedios and Lieberman, 2008).

This study mainly is consistent with previous studies that showed that curriculum planning in which the syllabus timetable and coverage is presented by teachers will lead to successful learning by students with effective teaching methods supported by resources and facilities made available during the class. These factors could support an effective evaluation and feedback process that will provide more efficient gain of knowledge and understanding that will eventually lead to improved student performance. 
Questions 3: "What do students need when the teachers plan their curriculum and cover their syllabus?"

Teacher responses regarding curriculum planning and decision making should not performed with a limited to few function considerations. One of these was only decided by numbers of principals of each department. Regarding the perception of the respondents towards syllabus coverage and the curriculum planning provided, the majority of teachers (about 20 out of 27) were satisfied. Three respondents stated "yes, it covers all curriculum goals and we got enough time for activities and practices". In addition, teacher nineteen stated that "yes it is effective as we can finish the case in due/time and also can plan our curriculum in a good way to help the weaker students keep a good check on their program", whereas nine teachers had comparatively lower satisfaction. However, regarding the negative impact of the syllabus coverage in the class, one teacher emphasized that "it helps, but for some cases it's very difficult to achieve all of planned learned outcomes within allotted time" where with not enough teachers recorded with supported responses, which are about two out of 27 of total responses. These results show the importance of putting teachers' opinions into consideration in determining their syllabus as a decision maker. In line with this, nine teachers noted that "the curriculum planning and coverage is not suitable and differ from the course tool with a gaps on the quantity and quality of students achievement" with the need to "review on the course planning by the teachers" to fit the content of the present course". These teachers may also be responsible for keeping records of student enrollment, attendance and evaluation, which can sometimes hamper the coverage of syllabus and course content during these periods (Aslam et al., 2012).

Therefore, it is remarkable that $85 \%$ of teachers are satisfied with the distribution of syllabus and curriculum content with sufficient time provided during the semester timetable. This result shows that syllabus coverage and regularity of class are closely associated. Regarding the high percentage of satisfied responses, this shows that the syllabus is well-designed with good timetable coverage, which should in turn reflect a good evaluation and student grades (Jadoon et al., 2012). In exploring the reason for the respondents who agreed with Aslam et al. (2012) and were dissatisfied and dissatisfied to some extent, most of these teachers expressed that they are busy with, for example, organizing and reviewing examinations or evaluating scripts and tutorial assignments. The results showed that due to some cultural issues, according to teachers' attitudes, they were afraid to provide truthful responses of the current situation, as it could affect their job or career (Alshehry, 2009).

\subsection{Teachers' Suggestions}

Teachers made the following suggestions to improve their teaching methods and performances in their colleges:

1. Sixteen teachers mentioned their attitudes and beliefs through improving their teaching methods, deciding their syllabus, and leading their classes by themselves as needed.

2. Twenty-two teachers emphasized that students should be required to evaluate their teachers reactions and discussion, critical thinking, self-learning and activities.

3. Seven teachers mentioned that student evaluations should be understood to be qualified.

4. Nine teachers stated that the school leaders should get their view about the curriculum and syllabus made and take it into their considerations by the teachers attitudes.

\section{Discussion of Results}

The interview data revealed in this study attached a great importance to the need to take the opinion, attitudes and suggestions of the teachers into consideration. This suggests that they recognized the importance of providing the science department with full equipment and instructional resources needed to enhance their teaching, activities, evaluation process and interactions of students during the class. In addition, the interview data illustrated that the most important obstacle revealed by teachers is the lack of student understanding of how the evaluation process should be performed, how to interact with their teachers during class, critical thinking, and independent learning. These results were often expected because of the international educational emphasis of these modern and updating methods of teaching science, getting away from traditional methods used on the academic achievement. Such a system in the higher educational institution does not take into consideration their individual needs, and students passing degrees is countered in terms of student success during examinations rather than the entire educational development of the students. At the same time, the interview data revealed that the teachers must be involved in some department administrative duties and decision making on what they need for successful dealing with discipline and teaching needs. However, teachers seemed to expect their students to independently solve their problem-based learning and addressing developmental needs. These findings are also consistent with the conclusions of DeHann (2005) and DeBurman (2004), which indicate the importance of decision making and show that some teachers are unclear about what methods of teaching should be used. Therefore, if the teachers understand their teaching role, the 
teachers' then should articulate their needs and rationale to the principals to perform their teaching tasks and deal with students' needs (Alkhazim, 2006)

To achieve the goal of good teaching and the need to adopt the best way of teaching methods in education, teachers have to choose from different techniques of teaching methods and strategies in colleges and classroom (Melita\&Peklej, 2007). Lesson planning is important before implementing lectures in class. Their selection of teaching methods is important on the basis of students' knowledge with some learning processes in the academic syllabus or curriculum (Carpenter, 2006). In addition, teaching methods and facilities provided need to be adopted by teachers to increase the learning abilities and achievement in effective ways such as presenting interactive lectures and group discussions during class to allow students express their opinions. Student presentation of seminars and workshops allows them to expand their knowledge (Henson and Eller, 2012). One effective teaching method is to involve students in learning activities and practice to promote their interest of mostly science content and develop scientific process skills. Innovative methods should be presented to students from time to time to give them a chance to integrate their knowledge into their existing ideas. Also, developing the teaching and method of science is mostly important to get student success about their learning process, interacted with their teachers and more satisfied about their learning and practices (Alshehry, 2009), as the study of Melita\&Peklej (2007) in higher educational system, teacher should emphasized by the principals or the department developing union to choose different techniques and strategies.

On the one hand, teachers attached little consideration to students' evaluations and feedback to connect this and consider it in the right way to be used in teaching processes and strategies, to assess students' learning and development need, and provide them with more educational improvements for their next levels. The level of exams and assessment involvement was perceived to be highest in the process of evaluations and educational issues. This indicates that the student evaluation feedback may depend on their grades, which would affect the reliability of the evaluation for both the teachers and their courses. In this case, the selected teachers showed the need to focus on all issues that students' faced to improve and solve all academic concerns. Meetings and discussions with students and providing workshops for them would help to develop the importance and understanding of the evaluation process. Further, the need for more conducting research in the future related to student needs and guidance program to develop their evaluation skills and background. However, developing the curriculum by teacher decision is important in that teachers usually understand their students' needs to best develop their understanding, knowledge and skills. This is consistent with the study of Carpenter (2006), which illustrated what the student learning process is based on in the teacher academic planning of syllabus or curriculum. Providing some training program, seminars and workshop by teachers to help cultivate skills to assess student needs would be a type of teacher professional development, allowing some sharing of extensive ideas regarding their experiences and previous knowledge about planning decision made on the curriculum (Alshehry, 2009).

The findings from this study reveal that for the teachers teaching and students learning to be successful, it is important that teachers have a positive and supportive academic environment in their department. This relationship requires that the leaders and the teachers in the same area of interest have to share an understanding of their decision making, roles and activities that the students would benefit from and evaluate their learning successfully (Henson and Eller, 2012).

A strong differences were found in teachers' perceptions of the idea and real situation of the college teaching and program in all three categories investigated in this study. Teachers believed that they could not carry out their tasks that would match their teaching performance and expectation, especially of conducting research related to their problems and professional needs. These results implied that teachers are not finding what they want from their students and the students as well. This however, might influence their academic evaluation in the achievement program and create a doubt regarding their value and performance. However, the interview findings from this study illustrated that some teachers insisted the need to participate in decision making, developing their professional role, improving their students understanding of evaluation process, and supporting of instructional resources constituted an important part of their beliefs. This underpins the conclusion that a non-supportive teaching environment is a negative issue affecting their performance.

\section{Summary and conclusion}

The aim of this study was to explore the perceptions of the academic teachers regarding their believed about how science is taught, lessons are planned and content is presented in higher education institutions in Saudi Arabia. It has attempted to examine the current situation of teaching science and the differences, and connecting this with the up to 
date and modern teaching process according to what is taught in advanced countries. Semi-structured interviews were used to collect the data from the respondents.

The findings of the interviews with participants generally encouraged as qualitative results with rich and deeper information that demonstrated other issues that were thought to be very important to improve the current teaching processes. These included students thinking and understanding, and teachers' professional development. The most impressive finding from this study was the widespread support expressed from beliefs of understanding teaching and students' learning process. It was found that there is a strong need to focus on the teachers participating in decision making in their teaching program, focusing on their professional development, training student to improve their understating of a successful learning process and skill. Despite this, there were many discrepancies' between the current study and the expectations.

The overall results suggest that decision making, teacher experience, beliefs, evaluation understanding and student learning have significant effects on the perceptions of teachers concerning approaches to educational achievement. In general, the results of the current research focuses on improving teaching performance on three main areas: lack of teacher professional development and decision making, lack of improving teaching instructional methods and lack of students' understanding of evaluation and critical thinking. The limitation of the present study gathers from its purpose and nature. It was contained to particular participants in one institution, which was subject to time constraints that prevented a large study from being undertaken. Further research should consider to investigate the view of other samples, such as principals and students.

\section{Implication and Recommendations}

The role of college system must be clearly specified to those participated in the presenting program, including teachers, principals and students. To this end, institutions related to the Ministry of Higher Education need to take the suggestions of staff (principals or teachers) into consideration, allowing some meetings as well as workshops and seminars to discuss the issues regarding their teaching role and how it could be improved. Furthermore, the Ministry of Higher Education allows each school to provide their own guidelines according to each location and environment need to consolidate and support their position in the college. The results of the findings suggest that the teacher performance of tasks depends on the provided regulation and chances to be part of the leader in the department. Therefore, teachers should keep communicate with other professionals in their fields, and participate in local and international conferences and training programs to discuss issues related to their teaching concerns, in particular, and development in general.

A significant recommendation is that teacher should have their rights and roles as they are the only one who would have the complete knowledge about the professional role with their students and offer them the adapted support they need. Moreover, the results of this study reflect an increasing recognizing and understanding among more recently appointed teachers of the importance of the current situation. This recognizing surely will indicate changes and supports the importance of informing teachers about the potential of teaching and learning programs though their future training and preparations.

\section{Acknowledgements}

I wish to extend my truthful gratitude to those who supported and encouraged me during my graduate experience and this research present study. Special gratitude go to the Ministry of Higher Education, Saudi Arabia for this sponsorship.

\section{References}

Abd-el Wassie, A. (1970). Education in Saudi Arabia. Glasgow: MacMillan.

Abdel-Al, Abdel-Fattah Ramadan. (1988). Education in the Kingdom of Saudi Arabia: A case study of the educational development in Saudi Arabia from 1926/27 to 1986/87. Al-Khobar: the New National Publishers \& Distributors.

Addison, WE \& Best, J. (2006). Students' Perceptions of Course Difficulty and their Rating of the Instructor. College Students Journal, 40 (2): 409-416.

Al-Dawood, A. S. (1996). Higher Education in the Kingdom of Saudi Arabia: Beginning and Development. Riyadh: Iracan Publication.

Alkhazim, M. A. (2006). The Higher Education in the Balance. Arabia Printing Publishing House, Riyadh.

Alshehry, A. T. (2009). Perceptions of Science Education for Girls in Saudi Arabia Higher Education: A Case Study of Female Biology Teachers. PhD Thesis, University of Nottingham, United Kingdom. 
Aslam, H. D., Younis, A., Sheik, A. A., Maher, M. Z. A. (2012). Analyzing Factors Affecting Students' Satisfaction regarding Semester System in Universities of Pakistan. Journal of American Science, 8 (10): 163-170.

Baki, R. (2004). Gender-Segregated Education in Saudi Arabia: its Impact on Social Norms and the Saudi LaborMarket EPAA, 12, 28. Available at: <URL: http//epaa.asu.edu/epaa/v12n28/>. [Accessed: 20.12.2007]

Bogdan, R. \& Biklen, S. K. (2003). Qualitative Research for Education: An introduction to Theory and Methods $\left(4^{\text {th }}\right.$ ed $)$. Boston, MA: Allyn and Bacon.

Carpenter, J. M. (2006). Effective teaching methods for large classes. Journal of family and consumer sciences education, University of Carolina, 24 (2): 13-23.

Cherry B., Ordonez L. D., Gilliland S. W. (2003). Grade Expectations: the Effects of Expectations on Fairness and Satisfaction Outcomes. Journal of Behavioral Decision Making, 16 (5): 375-395. http://dx.doi.org/10.1002/bdm.452

DebBurman, S. K. (2002). Learning How Scientists Work: Experiential Research Projects to Promote Cell Biology Learning and Scientific Process Skills. Cell Biology Education, 1, 154-172. http://dx.doi.org/10.1187/cbe.02-07-0024

DeHaan, R. L. (2005). The Impending Revolution in Undergraduate Science Education. Journal of Science Education and Technology, 14 (2): 253-269. http://dx.doi.org/10.1007/s10956-005-4425-3

Douglas, J., Douglas, A., \& Barnes, B. (2006). Measuring Students Satisfaction at a UK University. Quality Assurance in Education, 14 (3): 251-167. http://dx.doi.org/10.1108/09684880610678568

Goe, L., Bell, C., \& Little, O. (2008, June). Approaches to Evaluating Teacher Effectiveness: A research Synthesis. Washington, DC: National Comprehensive Center for Teacher Quality.

Henson K. \& Eller B. (2012). Educational psychology for effective teaching: $2^{\text {nd }}$ edition, Kendall Hunt Publishing co., pp. 5-10.

Jadoon, J. I., Jabeen, N., \& Zeba, F. (2012). Towards Effective Implementation of Semester System in Pakistan: Lessons from Punjab University, 2nd international Conference on Assessing Quality in HigherEducation, $1^{\text {st }}-3^{\text {rd }}$ December 2008, Lahore-Pakistan, 364-373. [online] Available: http://www.icaqhe2010.org/ (November, 2012).

Melita P. L., \& Peklej C. (2007). Motivation of Students Teachers in Educational Psychology Course: its Relation to Quality of Seminar Work and Final Achievement, University of Ljublijana, Department of Psychology, Ljubilijana, Slovenia, 16 (3): 5-25.

Pathak, T. \& Rahman, A. (2013). Perception of Students and Teachers towards Semester System: A Study in Some Selected Degree Colleges if Nagaon town of Nagaon District of Assam. Journal of Education and Practice, 4 (1): 84-91.

Remedios R., Lieberman D. A. (2008). I Liked your Course because you Taught me Wwell: the Influence of Grades, Workload, Expectation, and Goals on Students' Evaluations of Teaching. British Educational Research Journal, 34 (1): 91-115. http://dx.doi.org/10.1080/01411920701492043

Salamah, A. (2002). Methods of Teaching Science and their Roles in Thinking Development. Amman: Dar Alfekr Publishers\& Distribution.

Sarayrah, Y. (2003). Resistance to Innovative Teaching Methods in Public Administration Education in Jordan. International Association of Schools and Institutes of Administration. Available at: <URL: http://www.iiasiisa.be>. [Accessed 28-8-2008].

Smittle, P. (2003). Principals for EeffectiveTteaching. Journal of Developmental Education, 26 (3): 1-9.

Udovic, D., Morris, Dickman, A., Postlethwaite, J. \& Wetherwax, P. (2002). Workshop Biology: Demonstrating the Effectiveness of Active Learning in an Introductory Biology Course. Bioscience, 52 (3): 272-281. http://dx.doi.org/10.1641/0006-3568(2002)052[0272:WBDTEO]2.0.CO;2

Zaiton, A. (2004). Methods of Teaching Science. Amman: Shorok publication. 